\title{
Dynamic viscosity dependence on temperature for fuels used for diesel engine
}

\author{
Irina NIŢA $\breve{ }^{*},{ }^{1}$ Sibel OSMAN,${ }^{1}$ and Olga IULIAN ${ }^{2}$ \\ ${ }^{1}$ Department of Chemistry and Chemical Engineering, Ovidius University of Constanta, Bd. Mamaia 124, 900521, \\ Constanta, Romania \\ ${ }^{2}$ Department of Inorganic Chemistry, Physical Chemistry and Electrochemistry, "Politehnica" University of Bucharest, \\ Calea Grivitei 132, 010737, Bucharest, Romania
}

\begin{abstract}
Viscosity is an important property of fuels used for diesel engine affecting engine's efficiency and harmful gases emission. Viscosity of liquid fuels depends especially on fuels composition and temperature. The dynamic viscosity of diesel fuel, biodiesel and blends of diesel with biodiesel, $i$-propanol and $n$-butanol was measured for temperature ranging from $293.15 \mathrm{~K}$ to $323.15 \mathrm{~K}$ and atmospheric pressure. It has been verified that well-known Arrhenius derived equations can be used to estimate with good accuracy, viscosity at different temperatures for diesel, biodiesel, diesel+biodiesel blends, but also for diesel blends with propanol and butanol. Values of activation parameters: activation energy, activation enthalpy and activation entropy for the viscous flow were derived based on linearized Eyring's type equation. The values of the activation energy for viscous flow of fuels and fuels blends calculated based on measured values of dynamic viscosity in the temperature range of $273.15 \mathrm{~K}$ and $323.15 \mathrm{~K}$ were similar to those presented in the literature for some hydrocarbons, esters, and alcohols, respectively.
\end{abstract}

Keywords: dynamic viscosity; diesel, biodiesel; activation energy; viscous flow.

\section{Introduction}

Due to the concern raised by the increased environment pollution and the need to preserve oil resources, a trend has emerged in the last years, concerning fuels used in transportation: the use of biofuels as additives and/or substitutes for fossil fuels. Today, diesel fuel is commercialized blended with biodiesel. Other biofuels like bioalcohols are considered to be promising alternatives to diesel fuel.

Viscosity is an important property of fuels used for diesel engine $[1,2]$; it is related to fluid flow process and affects the fuel injection into the combustion chamber and the atomization quality [3-5], influencing fuel combustion and affecting engine's efficiency and harmful gases emission [6, 7].

Viscosity of liquid fuels depends especially on fuels composition and temperature, the pressure having a much lower influence. The dependency of the viscosity of diesel, biodiesel, and their blends on temperature was extensively investigated in the literature in the recent years [6, 8-14]. A reduced number of studies have addressed the issue of viscosity for diesel and biodiesel with bioalcohols blends [2, 15-18]. Diesel fuel and biodiesel follow the general behavior of liquids, their viscosity decreasing non-linearly with temperature increasing $[1,13,14,19,20,21]$. Modelling the viscosity dependence on temperature for diesel fuel and its blends with biofuels was often done with an Arrhenius type equation [5, 13].

Based on Arrhenius equation, the energy of activation for the viscous flow can be derived. Values of energy of activation for the viscous flow for pure substances like hydrocarbons, alcohols, esters and their mixtures are reported in the literature [21-24].

The Gibbs free energy of activation for viscous flow derived from viscosity data for methylcyclohexane has been reported of $13.3 \mathrm{~kJ} / \mathrm{mol}(298.15 \mathrm{~K})$ and varies for some methyl esters of fatty acids from $17.19 \mathrm{~kJ} / \mathrm{mol}$ (methyl decanoate) to $19.37 \mathrm{~kJ} / \mathrm{mol}$ (methyl tetradecanoate) [24]. Greater values of free energy of activation for viscous flow were reported in the literature at $298.15 \mathrm{~K}$ for methanol $(43.427 \mathrm{~kJ} / \mathrm{mol})$, ethanol (46.426 kJ/mol), and $n$-propanol (49.024 kJ/mol) [23].

The activation enthalpy for viscous flow for hydrocarbons like heptane and octane, alcohols like 1pentanol and 1-hexanol and their mixtures were calculated from the intercept of the straights lines representing the Gibbs free energy of activation for viscous flow dependence on temperature [21]. The activation enthalpy for the viscous flow for pure $n$ pentanol and $n$-hexanol was found to be approximately 2.6 times greater than the activation enthalpy for the viscous flow for $n$-heptane and $n$-octane, respectively. The activation enthalpy for the viscous flow at $298.15 \mathrm{~K}$ of some methyl esters of fatty acids (methyl decanoate, methyl dodecanoate, methyl tetradecanoate) were find to be of approximately 1.5 to 1.9 times greater than that of a hydrocarbon like methylcyclohexane [24].

As far as we know, values of energy of activation for the flow process for multicomponent systems like diesel, biodiesel and their blends with bioalcohols are not reported in the literature.

The aim of this paper is the study of dynamic viscosity dependence on temperature for diesel fuel, biodiesel, diesel+biodiesel, diesel+i-propanol, and

\footnotetext{
* Corresponding author. E-mail address: inita@univ-ovidius.ro (Irina Nita)
} 
diesel $+n$-butanol blends in terms of energy of activation for the viscous flow. The dynamic viscosity of diesel fuel, biodiesel and blends of diesel with biodiesel, $i$ propanol and $n$-butanol was measured for temperature ranging from $293.15 \mathrm{~K}$ to $323.15 \mathrm{~K}$ and atmospheric pressure. It has been verified that models derived from the well-known Arrhenius equation can be used to estimate with good accuracy, viscosity at different temperatures for diesel, biodiesel, diesel+biodiesel blends, but also for diesel blends with propanol and butanol. The dynamic viscosity dependence on temperature of diesel fuel, biodiesel and diesel blends with biodiesel, $i$-propanol and $n$-butanol respectively, is studied using Eyring's reaction rate theory and activation parameters for viscous flow are derived. Activation energy plays an important role in the evaluation of liquid flow properties. The values of activation energy for viscous flow could be used for analysis of molecular interactions existing in the blends.

\section{Experimental}

Diesel fuel and biodiesel were procured from a local company and they fulfil European standards quality requirements, EN 590 for diesel fuel and EN 14214 for biodiesel, respectively. $i$-Propanol of $99.0 \%$ purity, and $n$-butanol of $99.5 \%$ purity were supplied by Chemical Company, Romania. Properties of these fuels are listed in Table 1. Binary blends of diesel with biofuels were prepared by using an analytical balance having an accuracy of $0.0001 \mathrm{~g}$. Diesel+biodiesel blends with mass fraction of biodiesel of $0.105 ; 0.260 ; 0.513$, and 0.760 were prepared. Diesel+biodiesel blends were named Bdx.xxx, where X.xxx represents the mass fraction of biodiesel in the blend. Alcohols blends with diesel fuel were named Prox.xxx and Bux.xxx for diesel+ $i$ propanol and diesel $+n$-butanol blend, respectively. Diesel $+i$-propanol blend with 0.094 mass fraction of alcohol was named Pro0.094, and diesel $+n$-butanol blend with 0.097 mass fraction of butanol was named Bu0.097.

Dynamic viscosity was measured at atmospheric pressure by using an Anton Paar Stabinger viscometer model SVM 3000. The device has been previously described $[12,21]$. It is equipped with two measuring cells and provides the dynamic viscosity and density of the fuel sample at a desired temperature. The viscometer has a built-in Peltier thermostat which allows maintaining the sample temperature with an accuracy of $\pm 0.01 \mathrm{~K}$. The uncertainty of the dynamic viscosity is $0.35 \%$ and the uncertainty for density is $0.0005 \mathrm{~g} / \mathrm{cm}^{3}$. The measurements were done between $293.15 \mathrm{~K}$ and 323.15 K. Double-distilled water and dry air were used as reference fluids for the viscometer calibration.

Table 1. Properties of diesel fuel, biodiesel, $i$-propanol and $n$-butanol

\begin{tabular}{|l|c|c|c|c|}
\hline \multicolumn{1}{|c|}{ Property } & Diesel & Biodiesel & $\boldsymbol{i}$-Propanol & $\boldsymbol{n}$-Butanol \\
\hline Density at $20^{\circ} \mathrm{C}, \mathrm{g} / \mathrm{cm}^{3}$ & 0.8390 & 0.8846 & 0.7859 & 0.8114 \\
\hline Kinematic viscosity at $40^{\circ} \mathrm{C}, \mathrm{mm}^{2} / \mathrm{s}$ & 3.0110 & 4.5620 & 1.7438 & 2.2622 \\
\hline Cetane number & 46 & 52 & $12^{*}$ & $16^{*}$ \\
\hline
\end{tabular}

*from literature [25]

\subsection{Equations for viscous flow of liquid fuels}

An Arrhenius type equation was often used to express the viscosity dependence on temperature for diesel, biodiesel and their blends [5, 12]:

$$
\eta=A \exp \left(\frac{E_{a}}{R T}\right)
$$

where $\eta$ represents the dynamic viscosity; $E_{a}$ - activation energy for viscous flow; R - ideal gas constant; T absolute temperature; A - pre-exponential constant.

Based on Eyring's reaction rate theory, the Gibbs free energy of activation for the flow process can be calculated:

$$
\eta=\frac{h N_{A}}{V} \exp \left(\frac{\Delta G^{\neq}}{R T}\right)
$$

where h is Planck's constant; $\mathrm{N}_{\mathrm{A}}$ - Avogadro's number; $\mathrm{V}$ - molar volume; $\Delta \mathrm{G}^{\neq}$- free energy of activation for viscous flow.

Equation (2) can be linearized by applying the logarithm function:

$$
\ln \eta=\ln \frac{h N_{A}}{V}+\frac{\Delta G^{\neq}}{R} \frac{1}{T}
$$

The enthalpy and entropy of activation for viscous flow can be obtained if in Eq. (3), the free energy of activation for viscous flow is made explicit according to its thermodynamic definition relationship:

$$
\ln \left(\frac{\eta}{\frac{h N_{A}}{V}}\right)=\frac{\Delta H^{\neq}}{R} \times \frac{1}{T}-\frac{\Delta S^{\neq}}{R}
$$

where $\Delta \mathrm{H}^{\ddagger}$ and $\Delta \mathrm{S}^{\ddagger}$ are the enthalpy and the entropy of activation for viscous flow, respectively.

\section{Results and discussion}

The measured dynamic viscosity variation with temperature for diesel fuel and biodiesel (Fig. 1), diesel+biodiesel blends (Fig. 2), and diesel $+i$-propanol and diesel $+n$-butanol (Fig. 3) is graphically presented in order to better highlights the influence of temperature on the viscosity of these fuels. A nonlinear decrease in viscosity with temperature increasing for all investigated fuels and fuels blends as expected, was observed (Fig. 1-3). The influence of temperature on viscosity is more pronounced at low temperatures. A sharp initial decrease in viscosity with temperature increasing was registered for all investigated fuels and blends.

Empirical equations derived from the best known Arrhenius equation were used to calculate the viscosity of the studied fuels blends:

$$
\begin{aligned}
& \eta=\exp \left(A+\frac{B}{C+T}\right) \\
& \eta=\exp \left(A+\frac{B}{T}+\frac{C}{T^{2}}\right)
\end{aligned}
$$


where $\mathrm{A}, \mathrm{B}, \mathrm{C}$ are regression parameters.

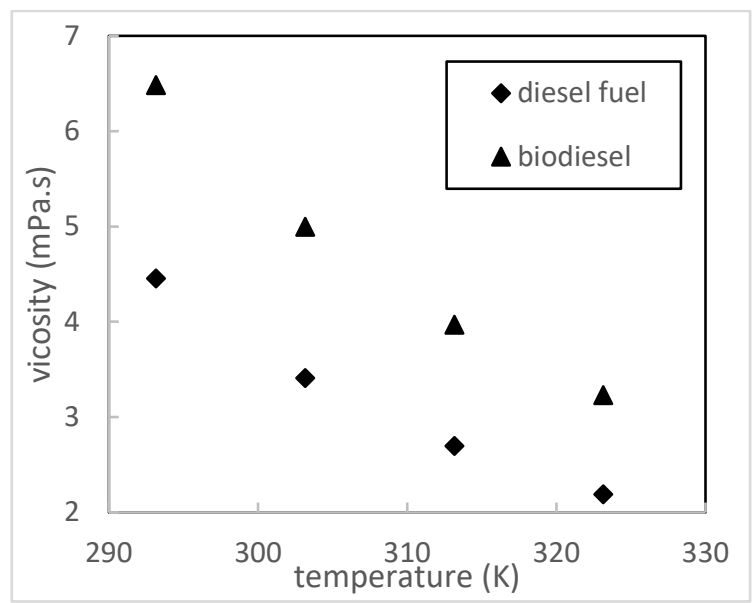

Figure 1. Viscosity versus temperature for diesel fuel and biodiesel

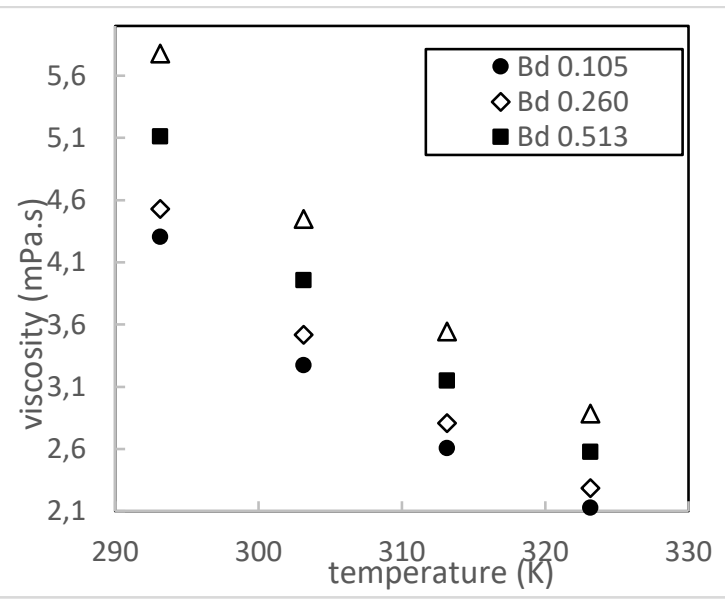

Figure 2. Viscosity versus temperature for diesel+biodiesel blends

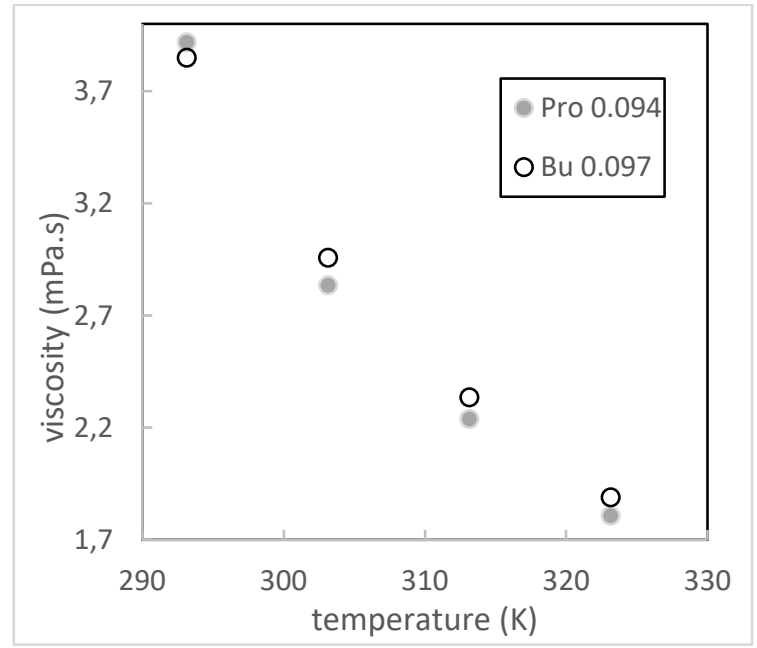

Figure 3. Viscosity versus temperature for diesel $+i$-propanol and diesel $+n$-butanol blends

The accuracy of viscosity estimation was evaluated in terms of average absolute deviation (AAD \%) calculated by the equation:

$$
A A D=\frac{100}{N} \sum_{i=1}^{N} \frac{\left\lceil\eta_{\text {exp }, i}-\eta_{c a l, i}\right\rceil}{\eta_{\text {exp }, i}}
$$

where $\mathrm{N}$ is the number of experimental points; $\eta_{\exp }, \eta_{\mathrm{cal}}$ - experimental and calculated values of viscosity.

Table 2 presents the value of regression parameters from Eqs. (5) and (6) and the corresponding AADs for the calculated dynamic viscosity of diesel+biodiesel blends and diesel $+i$-propanol and diesel $+n$-butanol blends for temperature ranging from $293.15 \mathrm{~K}$ to 313.15 K. It can be seen (Table 2) that Equation (5) estimates with good accuracy (AAD lower than 1.85\%) the viscosity dependence on temperature for the studied blends in the temperature range of $293.15 \mathrm{~K}$ to $323.15 \mathrm{~K}$ while the accuracy of Equation (6) is lower (AAD ranged from $13.23 \%$ to $16.31 \%$ ).

Straight lines were obtained by plotting $\ln (\eta)$ versus 1/T (linearized Arrhenius equation, Eq.1) for all investigated fuels and fuels blends, the correlation coefficient varying between 0.9950 and 0.9997 .

The graphical representations obtained for diesel and biodiesel are presented as example (Fig. 4). Derived values for activation energy of viscous flow, $E_{a}$, preexponetial constant $\mathrm{A}$, and the value of coefficient of correlation $\mathrm{R}^{2}$ are presented in Table 3 .

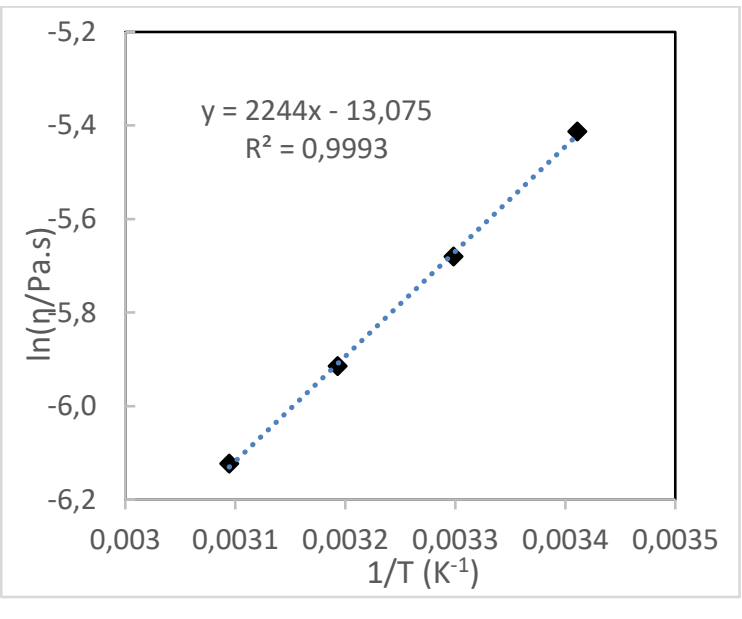

a

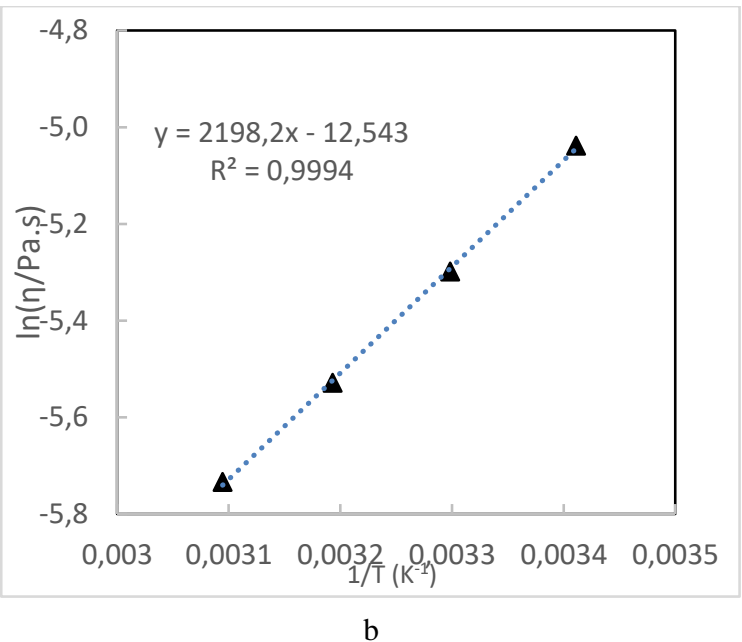

Figure 4. Graphical representation of linearized Eq. (1) for diesel fuel (a: $\downarrow$ ) and biodiesel (b: $\boldsymbol{\Delta}$ ). Experimental data (points) and correlation data ('---') 
Table 2. Values of regression constants A, B, and C from Equations (5) and (6) and corresponding AAD (\%) for the studied fuels and fuels blends

\begin{tabular}{|l|c|c|c|c|}
\hline \multicolumn{1}{|c|}{ Fuel } & A & B & C & AAD (\%) \\
\hline \multicolumn{5}{|c|}{ Eq. (5) } \\
\hline Bd0.105 & -1.94 & 392.82 & -177.80 & 0.14 \\
\hline Bd0.260 & -5.63 & 2017.69 & -10.29 & 0.40 \\
\hline Bd0.513 & -5.51 & 2008.92 & -11.47 & 0.63 \\
\hline Bd0.760 & -5.41 & 1999.41 & -13.83 & 0.61 \\
\hline Pro0.094 & -6.50 & 2165.37 & -17.21 & 1.86 \\
\hline Bu0.097 & -6.07 & 2089.60 & -11.09 & 0.50 \\
\hline \multicolumn{5}{|c|}{ Eq. (6) } \\
\hline Bd0.105 & 1.46 & 1.18 & 0.95 & 13.23 \\
\hline Bd0.260 & 1.51 & 1.25 & 1.03 & 14.04 \\
\hline Bd0.513 & 1.63 & 1.37 & 1.14 & 15.27 \\
\hline Bd0.760 & 1.75 & 1.49 & 1.26 & 16.31 \\
\hline Pro0.094 & 1.36 & 1.04 & 0.80 & 11.14 \\
\hline Bu0.097 & 1.34 & 1.08 & 0.84 & 11.75 \\
\hline
\end{tabular}

Table 3. Activation energy for viscous flow $E_{a}$, constant $A$, and coefficient of correlation $R^{2}$ from linearized form of Eq. (1)

\begin{tabular}{|l|l|l|l|}
\hline \multicolumn{1}{|c|}{ Fuel } & \multicolumn{1}{|c|}{$\begin{array}{c}\text { Ea } \\
(\mathbf{k J} / \mathbf{m o l})\end{array}$} & \multicolumn{1}{c|}{$\begin{array}{c}\mathbf{A} \\
(\mathbf{m P a} \mathbf{s})\end{array}$} & $\mathbf{R}^{\mathbf{2}}$ \\
\hline Diesel & 18.657 & 0.0021 & 0.9993 \\
\hline Biodiesel & 18.276 & 0.0036 & 0.9994 \\
\hline Bd0.105 & 18.458 & 0.0022 & 0.9984 \\
\hline Bd0.260 & 17.950 & 0.0029 & 0.9997 \\
\hline Bd0.513 & 18.013 & 0.0031 & 0.9993 \\
\hline Bd0.760 & 18.220 & 0.0033 & 0.9994 \\
\hline Pro0.094 & 20.191 & 0.0010 & 0.9950 \\
\hline Bu0.097 & 18.689 & 0.0018 & 0.9996 \\
\hline
\end{tabular}

Values of the activation energy for viscous flow close to those presented in Table 3 for diesel fuel $(18.657 \mathrm{~kJ} / \mathrm{mol})$ were found in the literature for benzene (14,955 kJ/mol, [26]) and $n$-heptane $(14.955 \mathrm{~kJ} / \mathrm{mol}$, [27]). The value of the activation energy found in the literature for $i$-propanol $(25.430 \mathrm{~kJ} / \mathrm{mol}[28]$ and 21.950 $\mathrm{kJ} / \mathrm{mol}[29]$ ) was close to that presented in Table 3 for diesel+ $i$-propanol blend, with low content of alcohol (Pro0.094: $20.191 \mathrm{~kJ} / \mathrm{mol}$ ).

As molecular motion, the flowing process of liquids depends on the interactive force among molecules so, it is related to the energy of activation for viscous flow. The energy of activation represents the minimum energy required for a molecule during the flow process to overcome the internal energy barrier, and to move from the original position to a nearby one represented by a hole. The energy of activation corresponds to this energetic state and the pre-exponential constant is correlated to the disorder corresponding to the viscous flow, so it is an entropic nature factor. It can be observed (Table 3) that the activation energy for viscous flow has relatively close values for diesel, biodiesel and their blends, ranging between $17.95 \mathrm{~kJ} / \mathrm{mol}$ and $18.65 \mathrm{~kJ} / \mathrm{mol}$. The activation energy for viscous flow for blends of diesel with low content of biodiesel, $i$-propanol and $n$ butanol respectively, varied in the order: $18.458 \mathrm{~kJ} / \mathrm{mol}$ $($ Bd0.105) < $18.689 \mathrm{~kJ} / \mathrm{mol}(\mathrm{Bu} 0.097)<20.191 \mathrm{~kJ} / \mathrm{mol}$ (Pro0.094).

The values of activation parameters for the viscous flow, $\Delta \mathrm{H}^{\ddagger}$ and $\Delta \mathrm{S}^{\ddagger}$ for the studied fuels and fuels blends were obtained from the graphical representation of $\ln (\eta)$ $-\ln \left(\mathrm{hN}_{\mathrm{A}} / \mathrm{V}\right)$ versus $1 / \mathrm{T}$. In this sense, for the constants grouping $\left(\mathrm{hN}_{\mathrm{A}} / \mathrm{V}\right)$, the value of the constant A calculated based on the graphical representation of Eq. (1) has been considered. Straight lines were obtained for all studied fuels and fuels blends by graphically representing Eq. (4). The entropy of activation for viscous flow was derived from the intercept with the ordinate, and the enthalpy of activation for viscous flow was calculated from the slope of the straight line. The graphical representations obtained for Bd0.105, Pro0.094 and Bu0.097 blends are presented as example in Fig. 5.

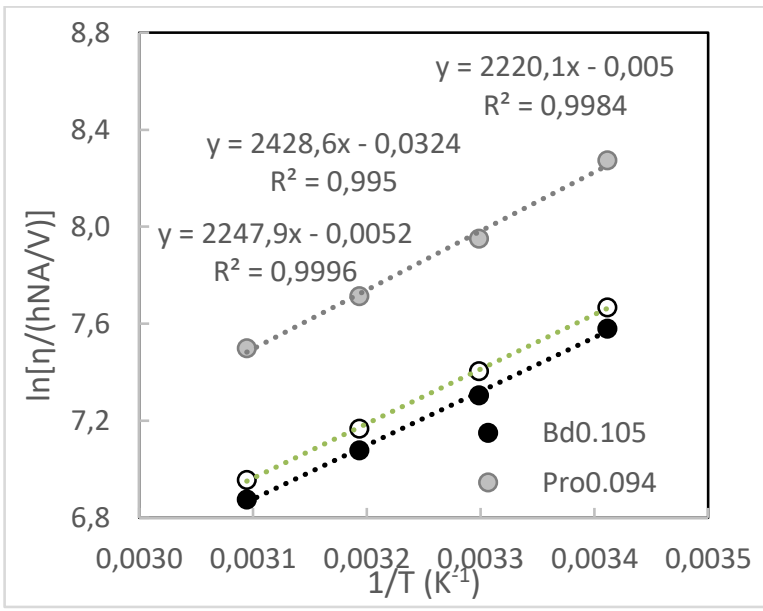

Figure 5. Graphical representation of Eq. (4) for calculation of activation parameters for the viscous flow. Experimental data (points) and correlation data ('---')

Table 4 presents the values of the enthalpy $\left(\Delta \mathrm{H}^{\ddagger}\right)$ and entropy $\left(\Delta S^{\ddagger}\right)$ of activation for viscous flow respectively, for the investigated fuels and fuels blends. Close values of the enthalpy of activation for viscous flow have been obtained for the studied fuels and fuels blends. The greatest value of $\Delta \mathrm{H}^{\neq}(20.191 \mathrm{~kJ} / \mathrm{mol})$ corresponds to diesel $+i$-propanol blend (Pro0.094), and the smallest value $(17.950 \mathrm{~kJ} / \mathrm{mol})$ corresponds to 
diesel+biodiesel blend (Bd0.260). The values of enthalpy of activation for viscous flow obtained for diesel, biodiesel and their blends are similar with values reported in the literature for methylcyclohexane, a diesel surrogate, and its blends with three different fatty acid methyl esters (methyl decanoate, methyl dodecanoate and methyl tetradecanoate) [24]. Values of $\Delta \mathrm{H}^{\neq}$very close to those obtained in this study for blends of diesel with $i$-propanol and $n$-butanol have been reported in the literature for mixtures of hydrocarbons (heptane or octane) with alcohols ( $n$-pentanol or $n$-hexanol) [21].

The contribution of the entropy of activation to the free energy of activation for the viscous flow is small (Table 4), resulting that the process is enthalpy controlled for the investigated fuels

Table 4. Values of the enthalpy $\left(\Delta H^{\ddagger}\right)$ and entropy $\left(\Delta S^{\ddagger}\right)$ of activation for viscous flow

\begin{tabular}{|c|c|c|}
\hline Fuel & $\begin{array}{c}\Delta \mathbf{H}^{\ddagger} \\
(\mathbf{k J} / \mathbf{m o l})\end{array}$ & $\begin{array}{c}\Delta \mathbf{S}^{\mp} \\
(\mathbf{J} / \mathbf{m o l} \cdot \mathbf{K})\end{array}$ \\
\hline Diesel & 18.657 & 0.0100 \\
\hline Biodiesel & 18.276 & 0.0690 \\
\hline Bd0.150 & 18.458 & 0.0416 \\
\hline Bd0.260 & 17.950 & 0.1305 \\
\hline Bd0.513 & 18.013 & -0.0914 \\
\hline Bd0.760 & 18.220 & 0.1189 \\
\hline Pro0.094 & 20.191 & 0.2694 \\
\hline Bu0.097 & 18.689 & 0.0432 \\
\hline
\end{tabular}

\section{Conclusions}

Experimental data of dynamic viscosity for diesel, biodiesel, diesel+biodiesel blends, and diesel $+i$ propanol, and diesel $+n$-butanol blends with low alcohol content are reported for temperature ranging from $293.15 \mathrm{~K}$ to $323.15 \mathrm{~K}$. Empirical equations derived from Arrhenius equation were tested to estimate dynamic viscosity of studied fuels at different temperatures. Eq. (5) gives good results (AAD $<1.86 \%$ ) in estimating the viscosity at different temperatures for all the studied systems.

It was observed that the studied fuels and fuels blends in the temperature range of $273.15 \mathrm{~K}$ to $323.15 \mathrm{~K}$ obey to the exponential Arrhenius behavior. Based on experimental dynamic viscosity data, values of two viscosity Arrhenius parameters, the activation energy for viscous flow and the pre-exponential constant were determined and compared with literature data.

The values calculated for the activation parameters of the viscous flow, $\Delta \mathrm{H}^{\ddagger}$ and $\Delta \mathrm{S}^{\ddagger}$ show that the flow process is enthalpy controlled for all the studied fuel systems.

\section{Conflict of interest}

Authors declare no conflict of interest.

\section{References}

[1]. M. Gullum, A. Bilgin, Measurements and empirical correlations in predicting biodieseldiesel blends' viscosity and density, Fuel 199 (2017) 567-577. Doi: 10.1016/j.fuel.2017.03.001

[2]. M. Lapuerta, J. Rodríguez-Fernández, D. Fernández-Rodríguez, R. Patiño-Camino,
Modeling viscosity of butanol and ethanol blends with diesel and biodiesel fuels, Fuel 199 (2017) 332-338. Doi: 10.1016/j.fuel.2017.02.101

[3]. D.C. Rakopoulos, C.D. Rakopoulos, R.G. Papagiannakis, D.C. Kyritsis, Combustion heat release analysis of ethanol or n-butanol diesel fuel blends in heavy-duty DI diesel engine, Fuel 90 (2011) 1855-1867.

Doi: 10.1016/j.fuel.2011.12.003

[4]. A. Jamrozik, The effect of the alcohol content in the fuel mixture on the performance and emissions of a direct injection diesel engine fueled with diesel-methanol and diesel-ethanol blends, Energy Conversion and Management 148 (2017) 461-476. Doi: 10.1016/j.enconman.2017.06.030

[5]. C.E. Ejim, B.A. Fleck, A. Amirfazli, Analytical study for atomization of biodiesels and their blends in a typical injector: Surface tension and viscosity effects, Fuel 86 (2007) 1534-1544. Doi: 10.1016/j.fuel.2006.11.006

[6]. B. Tesfa, R. Mishra, F. Gu, N. Powles, Prediction models for density and viscosity of biodiesel and their effects on fuel supply system in CI engines, Renewable Energy 35 (2010) 2752-2760. Doi: 10.1016/j.renene.2010.04.026

[7]. I.M. Atadashi, M.K. Aroua, A. Abdul Aziz, High quality biodiesel and its diesel engine application: A review, Renewable and Sustainable Energy Reviews 14 (2010) 1999-2008. Doi: 10.1016/j.rser.2010.03.020

[8]. K. Krisnangkura, T. Yimsuwan, R. Pairintra, An empirical approach in predicting biodiesel viscosity at various temperatures, Fuel 85 (2006) 107-113. Doi: 10.1016/j.fuel.2005.05.010.

[9]. S. Sani, M.U. Kaisan, D.M. Kulla, A.I. Obi, A. Jibrin, B. Ashok, Determination of physicochemical properties of biodiesel from Citrullus lanatus seeds oil and diesel blends, Industrial Crops \& Products 122 (2018) 702-708. Doi: 10.1016/j.indcrop.2018.06.002.

[10]. E. Alptekin, M. Canakci, Characterization of the key fuel properties of methyl ester diesel fuel blends, Fuel 88 (2009) 75-80. Doi: 10.1016/j.fuel.2008.05.023.

[11]. P. Benjumea, J. Agudelo, A. Agudelo, Basic properties of palm oil biodiesel-diesel blends, Fuel 87 (2008) 2069-2075.

Doi: 10.1016/j.fuel.2007.11.004.

[12]. L.F. RamírezVerduzco, B.E. García Flores, J.E. Rodríguez Rodríguez, A.R. Jaramillo Jacob, Prediction of the density and viscosity in biodiesel blends at various temperatures, Fuel 90 (2011) 1751-1761. Doi: 10.1016/j.fuel.2010.12.032.

[13]. R.E. Tate, K.C. Watts, C.A.W. Allen, K.I. Wilkie, The viscosities of three biodiesel fuels at temperatures up to $300{ }^{\circ} \mathrm{C}$, Fuel 85 (2006) 10101015. Doi: 10.1016/j.fuel.2005.10.015

[14]. M. Rushang, M. Joshi, J. Pegg, Flow properties of biodiesel fuel blends at low temperatures, Fuel 86 (2007) 143-151. Doi: 10.1016/j.fuel.2006.06.005

[15]. M. Lapuerta, R. García-Contreras, J. CamposFernández, M.P. Dorado, Stability, lubricity, viscosity and cold-flow properties of alcohol- 
diesel blends, Energy Fuel 24 (2010) 171-179. Doi: $10.1021 /$ ef100498u

[16]. J.J. Cano-Gomez, G.A. Iglesias-Silva, A new correlation for the prediction of kinematic viscosities of biodiesel + higher alcohols blends at atmospheric pressure, Fuel 237 (2019) 1254-1261. Doi: $10.1016 /$ j.fuel.2018.10.038

[17]. F. Pradelle, S.L. Sergio Leal Braga, A.R. Fonseca de Aguiar Martins, F. Turkovics, R.N.C. Pradelle, Experimental assessment of some key physicochemical properties of diesel-biodieselethanol (DBE) blends for use in compression ignition engines, Fuel 248 (2019) 241-253. Doi: 10.1016/j.fuel.2019.03.087.

[18]. I. Nita, S. Geacai, Study on density and viscosity for ternary mixtures biodiesel+diesel fuel+bioalcohols, Ovidius University Annals of Chemistry 23 (2012) $58-62$.

[19]. M. Cernoch, M. Hájek, F. Skopal, Relationships among flash point, carbon residue, viscosity and some impurities in biodiesel after ethanolysis of rapeseed oil, Bioresource Technology 101 (2010) 7397-7401. Doi: 10.1016/j.biortech.2010.05.003

[20]. A.F.M. Ebna, L. Poh-Seng, S.K. Chou, Y. Wenming, C. Yap, Experimental study and empirical correlation development of fuel properties of waste cooking palm biodiesel and its diesel blends at elevated temperatures, Renewable Energy 68 (2014) 282-288. Doi: 10.106/j.renene.2014.02.007.

[21]. A. Randová, L. Bartovská, Densimetric and viscometric study of liquid systems alkane + alcohol, Journal of Molecular Liquids 242 (2017) 767-778. Doi: 10.1016/j.molliq.2017.07.040

[22]. G.P. Dubey, M. Sharma, Acoustic, thermodynamic, viscometric and volumetric studies in binary systems of 1-decanol with nhexane, n-octane and n-decane with respect to temperature, Journal of Molecular Liquids 143 (2008) 109-114. Doi: 10. 1016/j.molliq.2008.06.015

[23]. M.S. Alam, B. Ashokkuman, A. Siddiq, The density, dynamic viscosity and kinematic viscosity of protic polar solvents (pure and mixed systems) studies: A theoretical insight of thermophysical properties, Journal of Molecular Liquids 251 (2018) 458-469.

Doi: 10.1016/j.molliq.2017.12.089.

[24]. D. Li, M. Guo, X. Wang, S. Lin, W. Jia, G. Wang, Measurement and correlation of density and viscosity of binary mixtures of fatty acid (methyl esters + methylcyclohexane), Journal of Chemical Thermodynamics 137 (2019) 86-93. Doi: 10.1016/j.jct.2019.05.021

[25]. E. Wansyah, R. Mamat, M.S.M. Sani, K. Sudhakar, A. Kadarohman, R.E. Sardjono, An overview of higher alcohol and biodiesel as alternative fuels in engines, Energy Reports 5 (2019) 467-479. Doi: 10.1016/j.egyr.2019.04.009

[26]. A. Messaadi, N. Dhouibi, H. Hamda, F.B.M. Belgacem, Y.H. Adbelkader, N. Ouerfelli, A.H. Hamzaoui, A new equation relating the viscosity Arrhenius temperature and the activation energy for some newtonian classical solvents, Journal of Chemistry 2015 (2015) 1-12. Doi: $10.1155 / 2015 / 163262$

[27]. C.K. Zeberg-Mikkelsen, G. Watson, A. Baylaucq, G. Galliero, C. Boned, Comparative experimental and modeling studies of the viscosity behavior of ethanol + C7 hydrocarbon mixtures versus pressure and temperature, Fluid Phase Equilibria 245 (2006) 6-19. Doi: 10.1016/j.fluid.2006.01.030.

[28]. A. Omrani, A.A. Rostami, M. Mokhtary, Densities and volumetric properties of 1,4-dioxane with ethanol, 3-methyl-1- butanol, 3-amino-1-propanol and 2-propanol binary mixtures at various temperatures, Journal of Molecular Liquids 157 (2010) 18-24. Doi: 10.1016/j.molliq.2010.07.015.

[29]. S. Akhtar, M.M.H. Bhuiyan, M.S. Uddin, B. Sultana, M. Nessa, M.A. Saleh, Viscosity of aqueous solutions of some alcohols, Physics and Chemistry of Liquids 37 (1999) 215-227. Doi: $10.1080 / 00319109908035923$.

Received: 23.05 .2021

Received in revised form: 28.06.2021

Accepted: 30.06.2021 